\title{
Making the Arctic predictable: The changing information infrastructure of Arctic weather and sea ice services
}

\author{
Maaike Knol ${ }^{a}$, Peter Arbo ${ }^{a}$, Paula Duske ${ }^{a}$, Sebastian Gerland ${ }^{b}$, Machiel Lamers ${ }^{c}$, Olga Pavlova ${ }^{b}$, Anders \\ Doksæter Sivle ${ }^{d}$, Stein Tronstad ${ }^{b}$ \\ a University of Troms $\varnothing$ - The Arctic University of Norway \\ ${ }^{\mathrm{b}}$ Norwegian Polar Institute \\ cWageningen University \\ ${ }^{\mathrm{d}}$ Norwegian Meteorological Institute
}

This is an Accepted Manuscript of an article published by Taylor \& Francis in Polar Geography on September 19, 2018, available online:

https://www.tandfonline.com/doi/full/10.1080/1088937X.2018.1522382

\begin{abstract}
This paper explores the changing infrastructure around weather and sea ice information provisioning for Arctic marine areas. Traditionally, the most important providers of operational information on sea ice and weather conditions are the national sea ice and meteorological services. More recently, the community of Arctic information providers has become more heterogeneous with the establishment of numerous collaborative platforms. Three case studies will enhance our understanding of current developments (BarentsWatch, Polar View and Arctic Web). We analyze their organization and funding structures, the types of services they develop, and their target groups. Based upon these cases, we discuss the information infrastructure's dynamics and underlying drivers of change. Apart from an expected need for customized services due to changing Arctic activity patterns, new initiatives arise due to a combination of (1) progress in information and communication technology, (2) a need to enhance interoperability of data systems, (3) and a desire to improve customized data conveyance from provider to user. The paper concludes with a discussion of the implications of the changing Arctic information infrastructure and defines directions for further research.
\end{abstract}

\section{Introduction}

The Arctic seems to be Janus-faced (Arbo et al. 2013). On the one hand, the Arctic is depicted as a region of opportunities, hiding large untapped resources and new shipping lanes, which will become more accessible due to receding sea ice (Howard 2009, Sale and Potapov 2010, Smith and Stephenson 2013). This is the image of the Arctic as the last frontier. On the other hand, there is growing concern about climate change and the effects of increased industrial activity in the Arctic. The Arctic is already warming twice as fast as the global average (AMAP 
2017), which is bound to have grave consequences for the ecosystems and human living conditions well beyond the region (ACIA 2005). In this image, the Arctic stands out as fragile, vulnerable and in need of preservation. Both approaches trigger efforts to improve mapping, surveying and monitoring capabilities in the Arctic (Lamers et al. 2016).

The combination of computers, radars, autonomous observation platforms, satellites and modern telecommunication systems has made a wide range of information available about climate, environment and operational conditions in the Arctic. These advances aim to enhance the controllability of operational and environmental risks in the area, turning the Arctic into an increasingly transparent and predictable area. Various environmental conditions and human activities can now be observed at a distance almost in real-time. Nevertheless, whereas advances in science and technology have greatly enhanced the ability to observe the vast and remote Arctic region, there are large information gaps in particular with concern to the marine areas. In addition, the High Arctic is remote in terms of digital accessibility. Poor geostationary satellite coverage has a number of effects on information sharing, for example lack of mobile phone coverage. The only (civilian) option above $80^{\circ}$ latitude is the Iridium constellation of satellites in low Earth orbit, with its erratic voice service and extremely limited bandwidth. In the past decades, many initiatives have been launched to address these concerns.

This paper explores the developments and dynamics of the systems providing information about weather and sea ice conditions in the Arctic. Recently, many new information providers and services have emerged, partly with different aims, organizational and funding structures, backgrounds, services and target groups. There are academic contributions that explore and map the growing diversity of Arctic data providers, primarily coordinated though the work of the Arctic Data Committee ${ }^{1}$ with the aim to enhance the interoperability of the various data and information systems (Pulsifer et al. 2014). There is also literature that explores the role and effects of Arctic information systems in specific sectors or geographical contexts (Stewart et al. 2010, Stephenson et al. 2011, Pulsifer et al. 2012, Lovecraft et al. 2013, Smith and Stephenson 2013). Recently, attention has been given to the changing role of environmental information in Arctic marine governance, including its role in empowering certain actors, standardizing processes and mitigating risks (Lamers et al. 2016). There are, however, no studies that discuss the dynamics of the Arctic weather and sea ice information infrastructure and how this might shape the wider development of Arctic activities.

This paper contributes to filling this gap by focusing on the following questions: What are the characteristics of weather and sea ice information provisioning related to the Arctic marine areas, and how is this infrastructure currently changing? What are the factors underlying these developments? To clarify these issues, we conducted case studies of new information platforms that deliver operational services to maritime end-users in the Arctic:

\footnotetext{
${ }^{1}$ The ADC was established in 2014 through a merger of the IASC Data Standing Committee and the SAON Committee on Data and Information Services. The ADC was launched to promote better coordination of scientific and data management activities in the Arctic.
} 
BarentsWatch, Arctic Web and Polar View. Prior to the work on this article, one of the coauthors conducted an assessment of geophysical information providers and platforms for the Arctic (Duske 2016), which functioned as a basis for the selection of the three initiatives. The three cases for this paper were selected for two main reasons: (1) their growing importance in providing information services to end-users, with a particular focus on European Arctic contexts; (2) their different traits with respect to their scope (e.g., geographical focus and type of services offered), organization and development path. Together, these three cases provide a relevant sample for analyzing the dynamics of Arctic weather and sea ice information systems. We used qualitative methods to collect empirical information, including in-depth interviews with nine representatives of information providers which were carried out in 2016 and 2017. Furthermore, we analyzed websites, reports and peer-reviewed literature.

In the next section, we provide the theoretical background and introduce the concept of infrastructure, which will support our analysis and conclusions later in the paper. Then, we introduce central elements of the Arctic weather and sea ice information infrastructure. We discuss the recent trend towards more heterogeneity in information provisioning and the ever-increasing number of collaborative information providers. This sets the stage for the presentation of the three case studies. Subsequently, we analyze the drivers behind and dynamics of these systems. Finally, we conclude with a discussion of the implications of the changing Arctic information infrastructure and define directions for further research.

\section{Information systems as infrastructure}

Arctic information systems in the field of weather and sea ice observation and forecasting constitute large sociotechnical systems (Mayntz and Hughes 1988). On the one hand, they consist of technological and material elements, such as weather stations (e.g., surface stations, ships, aircraft), instruments (e.g., radiosondes, autonomous platforms, satellite remote sensing), communication media (e.g., shortwave, VHF/MF and digital radio, cell phone networks, Navtex, satellite telecommunication), computational power and geographical information systems (GIS). On the other hand, the information systems fully depend on their social components, like organizations, knowledge (e.g., scientific theories, computer models, and algorithms), and standards and protocols, which are embedded in institutions and communities of practice with a shared understanding of the world. In order to function properly, the systems must be coordinated, funded, socially accepted, and people must be trained in order to use them. Thus, the social and material elements are intertwined and mutually dependent.

These complex sociotechnical systems make up the information infrastructure for the Arctic. We use the concept of infrastructure to account for the interrelated set of social, technological, and organizational components that act as the durable, connective tissues of society (Bowker et al. 2009, Edwards 2010, p. 8, Van Vliet et al. 2012). Infrastructures are the large-scale installations and organizational arrangements that extend across time and space and typically have a network structure, with nodes, links and hubs. Their main function is to facilitate the flow of goods, people, energy, information and so on. Since infrastructures 
underpin and are critical to a large number of activities and services, they are expected to run smoothly, be reliable and accessible, and make up seamless webs of sociotechnical systems. When they run smoothly, they appear as 'black boxes' (Winner 1993, Bijker et al. 2012) or tend to slip into the background. It has been argued that infrastructures are first really noticed when they fail (Star 1999). But also during their construction, infrastructures are not simply underlying structures, invisible and taken for granted (Howe et al. 2016). Hence, it is possible to look for infrastructures in the making. This implies exploring the choices that are made in the design of the infrastructures and understanding shifting relations (Bowker et al. 2009).

To study the development of Arctic weather and sea ice information infrastructures, we also need a conceptual understanding of the stages through which new infrastructures commonly develop (Edwards et al. 2007). At the beginning, system builders conceptualize, create and promote new systems. They link and combine sets of devices that can fill a functional need. For a system to become successful, system builders have to mobilize support while simultaneously handling the technical, organizational, financial, political, legal and marketing challenges of the new system. Once a system has been successfully constructed, it grows through technology transfer and user adoption. This process always entails innovations and variations of the original system design. The system has to be scaled up and incorporate more heterogeneous users and contextual elements. The users frequently shape the system in their own ways, and competing systems may arise. In the third stage, there will be a consolidation. One system outcompetes the others or new technologies and standards are developed that allow previously incompatible systems to interoperate. By the creation of gateways, multiple systems are linked into networks. Finally, the infrastructure can be superseded or split into more specialized elements (ibid).

Governments have played important roles in the development and consolidation of information infrastructure. Infrastructures have often been perceived as public goods, catered for by monopoly providers. Since the 1980s, this traditional, government-led model has been challenged by a market-oriented approach, emphasizing deregulation and competition (Schneider and Jäger 2003, Kessides 2004). Spurred by a neoliberal approach and facilitated by new information technologies, there has been an expansion of independent suppliers of information, which led to distributed control and coordination. New information technology permits integration of services across networks. The inherent tension in infrastructures between standardization and flexibility (Hanseth et al. 1996) can thereby be resolved, and in recent decades, more and more new services are built upon existing infrastructures.

With the trends of increasing globalization, digitalization and commercialization, the development and maintenance of infrastructures has become a more controversial political theme. Issues of concern include costs, access, user-friendliness, the risk of breakdown, ecological impacts, and security (Flyvbjerg et al. 2003, Dunn Cavelty and Kristensen 2008). Another important phenomenon is the rise of digital platforms, which share many of the characteristics of infrastructures, but which also represent a new business model where revenue streams are generated through intermediation and control of network effects 
(Plantin et al. 2016, Langley and Leyshon 2017). In the next section, we explore some of the particularities of the Arctic weather and sea ice information infrastructure.

\section{Arctic weather and sea ice information provisioning}

Many different social, material and technological elements together make up the Arctic weather and sea ice infrastructure. While one can speak of a global public-private weather enterprise (Thorpe 2016), the most central institutions have traditionally been, and still are, the public national meteorological services (NMS). The NMS collect data from a variety of instruments on the ground and at sea, as well as air- and spaceborne instruments. These data are translated into information through data assimilation and analysis methods, numerical modelling approaches, statistical post processing and visualization techniques. Some NMS also use paleoclimatic approaches and model- and observation-based re-analyses for giventime periods (see Overpeck et al. 2011). While much of the data is produced through their own measurement devices, NMS have grown increasingly dependent on externally produced data, such as satellite imagery from space agencies and observations from ships or aircraft. Since meteorology as a science developed in conjunction with the advancement of other sciences and technologies (Hunt 2013, Nilsen and Vollset 2016) the NMS are deeply embedded within a larger infrastructure.

While forecasting activities for Arctic marine areas are not necessarily different from areas at lower latitude, some issues are specific for Arctic marine areas. Generally, numerical weather prediction models show lower capability at high latitudes when compared to other regions (Jung et al. 2016). This is partly due to the scarcity of in-situ observations, and partly because most of these models are designed for the mid-latitude range and not for the Polar Regions.

Some parameters are particularly important for users in Arctic marine settings. Wind and wave information are often requested by users, such as ferry operators or fishers, and seen as crucial when undertaking Arctic maritime activities (MET Norway 2015). Of special interest are certain low-pressure systems that develop in the atmosphere, called Polar Lows. Polar Lows are mesoscale cyclones that can occur rapidly during wintertime. They can cause very fast changes in weather conditions, bringing strong winds and heavy snow, which creates dangerous conditions for vessel operations. Despite improvements in recent years, they can be challenging to predict, due to their rapid development and the relatively scarce observation network in this area (Rojo et al. 2015).

Additionally, poor visibility caused by heavy snow (wintertime) and dense fog (summertime) can influence navigation in the Arctic. During the winter, another major concern for marine activities in the Arctic is sea spray icing (Samuelsen et al. 2017). Depending on wind speed, wave characteristics, and air and water temperature, large amounts of ice can be accreted on ships or other constructions. This ice might cause instability for vessels resulting in extreme rolling or capsizing, with the danger of loss of lives or goods (Samuelsen et al. 2017). Despite the fact that Arctic coastal states NMS' forecast these typical weather conditions, weather poses a threat to maritime activities due to harsh conditions, and because 
it is not always possible to forecast phenomena like Polar Lows early enough for people to take precautions.

Sea ice information services are also vital for maritime actors in large parts of the marine Arctic areas. The most important operational information services are traditionally developed by the national Ice Services, which are often based at the NMS. For instance, in Norway, the Norwegian Meteorological Institute is responsible for relaying ice charts that cover the Atlantic part of the Arctic to its users ${ }^{2}$. The ice charts are published daily, except during weekends. Key users are cruise ships, research vessels, the Coast Guard and shrimp vessels that move close to the ice edge in the northern and southeastern part of Svalbard. The Ice Services base their charts primarily on satellite imagery. Some observations from ships, coastal stations and aircraft are available, however, due to their restricted availability they are of limited importance from an operational perspective.

With growing interest in weather and sea ice information, many new collaborative platforms have been established in the past decade to deliver customized services to specific users beyond those that the NMS can provide - a trend amplified by the International Polar Year 2007-2008 that encouraged developments in the field of polar data management (see Pulsifer et al. 2014).

Programs and observational activities can be found from local to global level. There are several international information initiatives that cover both the Arctic and Antarctic, such as Polar View and EU-PolarNet. Numerous pan-Arctic examples exist, many of which are linked to the Arctic Council, such as the Arctic Spatial Data Infrastructure, the Arctic Monitoring and Assessment Program, and the Sustaining Arctic Observing Networks. Bilateral initiatives include Barents Portal, which is a collaborative project between Norway and Russia and covers the cross-border Barents region. Finally, there exists a large number of Arctic information initiatives at the state level, which are, in most cases, funded by national programs. Their geographic focal area includes primarily territorial waters and the states' Exclusive Economic Zones. Examples are BarentsWatch in Norway and the Alaska Ocean Observing System in the US.

Some initiatives aim to provide information and decision support to specific users, but many are research oriented and serve as arenas for the exchange of Arctic information and knowledge. There are, for example, many sea ice datasets available, providing information on concentration, type, thickness and drift of sea ice. A variety of data centers manage and distribute the scientific data, create tools for data merging and processing, support users, perform scientific research and educate the public about the cryosphere ${ }^{3}$. Hence, there is an Arctic information 'ecosystem', encompassing a large and heterogeneous patchwork of initiatives and platforms (Pulsifer et al. 2014). Below, we present three initiatives that deliver

\footnotetext{
${ }^{2}$ The Ice Service of the Norwegian Coastal Administration informs vessels about the sea-ice situation in Norwegian waters in the Skagerrak Strait from the Swedish border to Kristiansand.

${ }^{3}$ These include the National Snow and Ice Data Center in Boulder, Colorado (NSIDC), which provides the longest records of sea-ice concentration and drift, OSI-SAF (European-international), IFREMER (France), MET (Norway), SEAICE.de (Germany), the University of Bremen (Germany) and MOSJ (Norway). See https://sites.google.com/site/arcticseaicegraphs/ for an overview of various sea-ice portals.
} 
operational services in more detail: BarentsWatch, Arctic Web and Polar View. These are important collaborative efforts that aim to build customized information for targeted user groups by combining existing data and information sources.

\section{BarentsWatch}

BarentsWatch ${ }^{4}$ is a Norwegian initiative that focuses on coordinating and disseminating information to provide a more comprehensive picture of the activities in, and conditions of, marine areas. It covers the ocean and coastal areas from Denmark in the south, to Greenland in the west, the North Pole in the north and Novaya Zemlya in the east, however, most of the geographical focus is on Norwegian waters and its Exclusive Economic Zone. The Norwegian Minister of Foreign Affairs and the Minister of Fisheries and Coastal Affairs launched BarentsWatch in May 2012. It was established as part of the government's focus on the High North. BarentsWatch is subject to the Ministry of Transport and Communications, and the Norwegian Coastal Administration (NCA) has responsibility for its implementation. Ten ministries and 29 research institutes and government agencies cooperate in this effort and provide input into the system.

BarentsWatch offers open as well as restricted information services within the maritime domain. The open information portal provides information about the environment and climate, Arctic ecosystems, maritime transport, oil and gas, fisheries and aquaculture, and maritime legal boundaries. Furthermore, there are specific information and/or forecast services. These include: (1) a Polar Lows forecast and warning service, which is based on data from the Norwegian Meteorological Institute, including its Twitter messages; (2) a wave forecast service for selected fairways on the Norwegian coast, which is updated four times daily $^{5}$; (3) FishInfo - a service that intends to facilitate fishing operations through mapping tools that provide information about, for example, planned and ongoing seismic surveys, the location of the ice-edge, and the location of stationary fishing gear (updated continuously by the Coast Guard services); (4) a harbor map service to provide detailed information about facilities and services, however not intended for navigational use. The latter is based on the Coastal Administration's "Havnebase" (harbor database), but the individual ports have the responsibility to update information about their services and facilities. Target groups are the public administration, industry and actors within research and education. The fisheries are an important user group of the open services.

The information services are accessed primarily via the website. In an interview (June 2016), a representative of BarentsWatch argued that the services could be enhanced if the information could be conveyed through the navigation systems on board of ships. However, to enable such an infrastructural development, there are many technological and legal

\footnotetext{
${ }^{4}$ https://www.barentswatch.no/

${ }^{5}$ The company Polytec delivers the actual service, based on data from the Norwegian Meteorological Institute and the U.S. National Weather Service.
} 
challenges to overcome. It is currently discussed at the international level if there are openings for such enhancements in eNavigation ${ }^{6}$.

BarentsWatch has two restricted sections accessible to authorized government agencies only. One of these sections deals with crime detection and prevention (such as illegal, unreported and unregulated fishing) and the other facilitates rescue operations. These sections and their content are determined by the cooperating authorities. The restricted services are aimed at supporting marine authorities with an operational responsibility in the Norwegian Exclusive Economic Zone and coastal areas (e.g. police, customs, Norwegian Armed Forces, Directorate of Fisheries, the Norwegian Maritime Authority, the Norwegian Coastal Administration and the Joint Rescue Coordination Centres) ${ }^{7}$.

BarentsWatch is user-driven to the extent that needs are mapped and prioritized in dialogue with the relevant user groups and agencies. Meetings are organized in which different user groups present their needs for information and services. An annual stakeholder conference allows for network building and the sharing of knowledge and information needs.

\section{Arctic Web}

Arctic Web originated as a Danish initiative initially coordinated by the Danish Maritime Authority (DMA). Its aim is to improve maritime safety in Arctic waters through providing eNavigation functionalities. The geographic focal area of Arctic Web is the entire Arctic, though services have initially focused primarily on waters within the Kingdom of Denmark, most importantly Greenland waters.

Arctic Web functions as a web application that collects and presents information relevant for safe navigation in Arctic regions. This includes tailored ice charts and weather forecasts based upon a vessel's position and planned route, as well as information about other ships in the area, navigation warnings, and search and rescue information. A vessel receives the services from Arctic Web on its "third display" (next to the obligatory chart and radar displays) and only needs a computer and Internet connection to use Arctic Web. Hence, Arctic Web does not interfere with navigational instruments. In order to use the services, vessels must register with their Marine Mobile Service Identity number and name. Then, they are granted access to all functions in Arctic Web. Currently, all services can be used free of charge.

Arctic Web is based on information technology, data sharing and management. It is developed in open layers, which can be shared across the maritime community and used by others. The application reduces data volumes and, with that, costs. Arctic Web synthesizes and combines data from various sources and compresses relevant information for its users. By customizing data for a particular user and route, the locally cached data is of smaller size and therefore easier and cheaper to transmit and display.

\footnotetext{
${ }^{6}$ The International Maritime Organization (IMO) defines eNavigation as "the harmonized collection, integration, exchange, presentation and analysis of marine information on board and ashore by electronic means to enhance berth to berth navigation and related services for safety and security at sea and protection of the marine environment".

http://www.imo.org/en/OurWork/safety/navigation/pages/enavigation.aspx

${ }^{7}$ https://www.barentswatch.no/en/about/
} 
The data and information that Arctic Web makes use of is delivered from different cooperating partners. The Danish Meteorological Institute has been actively involved in the development of Arctic Web, providing ice charts and weather forecasts for Greenland. Other important partners are the Danish Defense Centre for Operational Oceanography that provides weather and ice information for the North Atlantic Treaty Organization around Greenland. A variety of organizations are involved in the development of Search and Rescue functionalities, such as the Iceland Coast Guard, the Danish Ministry of Defense and the Joint Arctic Command.

For Arctic Web, cruise operators form the most important user group. In 2016, about 120 vessels were registered members of Arctic Web. To respond to the specific needs and desires of end users, Arctic Web set up surveys and focus groups when it was newly established (personal communication, June 2016). This resulted in close collaboration for new developments and testing new services with cruise companies like Oceanwide Expeditions, Hurtigruten and Princess Cruises. Furthermore, Arctic Web is in regular dialogue with the larger umbrella organizations for cruise operators - the Cruise Lines International Association (CLIA) and the Association of Arctic Expedition Cruise Operators (AECO).

Arctic Web's organizational set-up has changed throughout its development. As mentioned above, DMA initiated it as an internal project and coordinated Arctic Web with additional funding from the Danish Ministry of Defense. From early 2015, the Nordic Council of Ministers supported the project financially for three years (until the end of 2017). DMA has been concerned to ensure a realistic operational set up for the future of Arctic Web and the continued improvement of navigational safety in the Arctic (personal communication). In 2018, the Norwegian Coastal Administration (NCA) - which also coordinates and runs BarentsWatch - agreed to take over the ownership. While the focus has been primarily on Greenlandic waters, an expansion can be expected as the NCA has taken over ownership. This might imply closer collaboration with other Norwegian partners, like MET Norway. A form of integration with BarentsWatch could also be anticipated, however, since the vast part of the research for this article was carried out in 2016 and 2017, we are not able to elaborate on the potential implications of shifting ownership.

\section{Polar View}

While Barents Watch and Arctic Web can be characterized as public initiatives, Polar View 8 can be characterized as an institution that brings together public, academic, and private sector organizations. The genesis of Polar View began 15 years ago as a result of a series of contracts with the European Space Agency and the European Commission to foster monitoring of the polar regions using earth observation satellites. When those contracts came to their conclusion, the participants had a shared desire to continue to collaborate and build upon what they had achieved. In 2011, Polar View was incorporated as a not-for-profit corporation.

\footnotetext{
${ }^{8}$ www.polarview.org
} 
As such, it has members, rather than shareholders, from over 20 organizations across Europe and North America.

Today, Polar View works to make observation systems more accessible to stakeholders interested in the Polar Regions; to influence policy regarding monitoring and data management; to coordinate and provide integrated information services; and to define service delivery requirements and conduct trials and demonstrations.

Polar View services provide information related to resource development, safety of operations, environmental protection and sustainable economic growth. That information concerns sea ice, icebergs, lake and river ice, snow cover, and glaciers. Users of the services include northern communities, marine vessels, oil and gas companies, emergency services, and science and research organizations. The information is available both for free and fee-forservice, depending on the degree of customization required.

The services particularly relevant for vessel operators are the Polar View Data Portal and the Polar Code Decision Support System. The first provides free access to near-real-time satellite data (Sentinel 1 SAR, MODIS), ice concentration information (based on AMSR2), and ice charts from the Norwegian and United States ice services. Data is available for both the Arctic and Antarctic in formats for both high and low-bandwidth connections. The Polar Code Decision Support System provides ships operating in the Polar Regions with information to meet the requirements of the new IMO Polar Code, such as sea ice, meteorological, safety, and environmental data. The solution consists of aggregated historical information; near-realtime information obtained from satellites; forecasted information obtained from models; and a data infrastructure that enables the processing and delivery of the information to land-based support systems and over low-bandwidth channels to ship bridges. A risk analysis algorithm assesses the danger posed to a ship by the ice regimes it will encounter on a voyage. Visualization tools allow the ship and its shore-based support to see and assess the information that has been provided (personal communication).

Polar View also delivers services to indigenous users, in particular through its Community Ice Service, which provides sea ice information to Inuit hunters in the Canadian Arctic, Greenland, and Alaska. Another user group are researchers and analysts. Through the Polar Thematic Exploitation Platform, intermediate users get access to large volumes of earth observation satellite data and other data types, high performance computation and storage, polar-themed algorithms, and tools for online collaboration. The concept is to bring users and their algorithms to the data, rather than having users download large volumes of data locally (personal communication). 
Table 1: A comparative overview of BarentsWatch, Arctic Web and Polar View

\begin{tabular}{|c|c|c|c|}
\hline & BarentsWatch & Arctic Web & Polar View \\
\hline $\begin{array}{l}\text { Geographical } \\
\text { focus }\end{array}$ & $\begin{array}{l}\text { Primarily Norwegian } \\
\text { waters }\end{array}$ & Primarily Greenlandic waters & $\begin{array}{l}\text { Both polar regions and the } \\
\text { cryosphere }\end{array}$ \\
\hline Type of services & $\begin{array}{l}\text { A diversity of information } \\
\text { tools and warning } \\
\text { services, covering among } \\
\text { others Polar Low } \\
\text { warnings, wave warnings, } \\
\text { harbor information, and } \\
\text { interactive maps for } \\
\text { fisheries }\end{array}$ & $\begin{array}{l}\text { eNavigation services, including weather } \\
\text { and sea ice forecasts, information about } \\
\text { other vessels' location and Search and } \\
\text { Rescue resources }\end{array}$ & $\begin{array}{l}\text { Near real time } \\
\text { products/analyses of sea } \\
\text { ice, lake and river ice, } \\
\text { glaciers, and snow cover }\end{array}$ \\
\hline Operator & $\begin{array}{l}\text { Norwegian Coastal } \\
\text { Administration }\end{array}$ & $\begin{array}{l}\text { Danish Maritime Authority (2011-2018) } \\
\text { Norwegian Coastal Administration (2018- } \\
\text { ) }\end{array}$ & Polar View ApS \\
\hline Access & $\begin{array}{l}\text { Freely accessible services } \\
\text { (applies to the open } \\
\text { section) }\end{array}$ & $\begin{array}{l}\text { Non-commercial services accessible upon } \\
\text { registration }\end{array}$ & $\begin{array}{l}\text { Commercial and non- } \\
\text { commercial services }\end{array}$ \\
\hline
\end{tabular}

\section{Arctic information systems: drivers and dynamics}

Above we have presented examples of the recent construction of three Arctic information platforms (see also Table 1), which can be perceived as infrastructure in the making. Based on these examples, and on the wider literature on Arctic information systems, we analyze the development of information infrastructures in the Arctic, particularly by focusing on the drivers behind the establishment of these platforms, as well as on their specific dynamics.

What stimulates the development of the Arctic weather and sea ice information infrastructure? Naturally, there is an expected need for new and partly customized services when navigational activity is increasing and entering previously uncharted areas. Some of these needs are driven by the new Polar Code requirements for information. While the need for services forms the main rationale for these platforms, a set of other underlying catalysts for their development should be acknowledged.

A first essential driver is the advancements in information, communication and satellite technology. These technologies play an indispensable role in Arctic information provisioning in general, and the development of computer sciences opens new opportunities for combining and customizing data. Many of the Arctic information initiatives build on the development of new technologies for enhanced data customization and information 
provisioning. State-of-the-art services include eNavigation tools and interactive mapping services.

A second driver behind the establishment of new information platforms is the existing challenges in Arctic data management and data sharing, especially with regard to sea ice data. Many data sets are difficult to find, access and combine (Eicken 2013). They are governed through a patchwork of organizations (Pulsifer et al. 2014) with 'no interconnected suite of institutions or a single comprehensive process that governs the [sea-ice] system as a whole' (Lovecraft et al. 2016). Lack of data is thus not a main issue; it is rather the lack of resources to combine data sources for specific needs. This relates to the costs and complications connected with data source accessibility, data conveyance from source to service provider, and to data transformation, which is often required on the way from source data to end product. The initiatives described in this paper partly originated from the need and desire to combine and process various data sources into more usable information for targeted interests. They are attempts to establish more effective partnerships to enhance interoperability of the various systems and organizations, that is, to improve the ability to work together on many levels (Pulsifer et al. 2013).

A third underlying driver is the problems that end-users have when accessing data, or trying to access data, in the remote Arctic (Lamers et al. 2018). Data conveyance - moving the data from the service provider to a vessel operating in the Arctic - with limited connectivity is a key challenge in remote Arctic regions where availability of the Internet and communication services are poor. The result is that ship operators are unable to download large amounts of data on low bandwidth. At particular points in time, these users need special deliveries of data about a particular geographic location. Data have to be compressed to overcome the bandwidth limitations at high latitudes. The information needed is thus often a small percentage of the information included in the standard products from the traditional services. The services that Arctic Web and Polar View provide are illustrative of the recognized need to provide users with a customized subset of available data, tailored to a vessel's location or planned route.

Thus, the changing Arctic weather and sea ice infrastructure not only reflects the changes in activity patterns in the Arctic, but results from a combination of (1) progress in information and communication technology, (2) a need to enhance interoperability of data systems, (3) as well as from a desire to improve customized data conveyance from provider to user.

Understanding the nature of an evolving infrastructure requires that the emphasis is not on the components of the infrastructure, but rather on its changing relations (Bowker et al. 2009). What is striking in the analysis of the three cases presented above, is the increasingly networked character of Arctic information provisioning with the trend towards more collaborative platforms. There is a shift from centralized control to more distributed forms of control and coordination. While the traditional weather and sea ice information infrastructure is highly networked, there are many more connections and interdependencies in the current Arctic information ecosystem due to different types of data, expertise and technologies 
involved. What becomes apparent, though, is the central position that the NMSs take in these new infrastructures. Whereas the national meteorological institutions are partners in the national examples (BarentsWatch for Norway and Arctic Web for Denmark), there are as many as four different NMS involved in the international platform of Polar View. This can be explained by the fact that the basic infrastructure for providing meteorological observations is organized by states through their national meteorological institutes, which all systematically collect and distribute measurements, including data that are obtained from outside these organizations (Hunt 2013).

Another issue that becomes apparent is that many initiatives in Arctic information provisioning are initially established on project-based resources (Duske 2016). An example like BarentsWatch, which from its inception was a long-term initiative rather than a project with a limited period, seems to be an exception rather than the rule. The cases that we have presented are in different phases of their establishment. While Polar View evolved into a notfor-profit corporation from its initial project structure, the ownership and management of ArcticWeb was transferred to a Norwegian platform operator in 2018. Hence, many initiatives struggle or have struggled to become part of a durable infrastructure in Arctic information provisioning and need to find workable solutions to cover the costs associated with running the infrastructure. This, in turn, challenges the ideal of free services and the idea of a shared infrastructure in the sense of it being a public good (Bowker et al. 2009).

\section{Governance challenges and research needs}

This paper discussed developments in the field of Arctic information systems. It described the transforming ecosystem of Arctic information provisioning with its highly heterogeneous and networked character and focused on the collaborative information platforms that arise across the Arctic: initiatives that aim to respond to the current needs for data and information sharing in a time of rapid environmental change. To date, little attention has been paid to these infrastructures. Hence, we introduced the concept of infrastructure in the analysis of Arctic information systems to take account of their social and organizational dimensions (Bowker et al. 2009). To conclude, we present four themes that require further academic consideration.

In the literature on information infrastructure, it is acknowledged that engaged participation in the formation of infrastructure elements might create deeper awareness of alternatives and thus enhance uptake, which calls for a forum where multiple perspectives can be considered and where tensions are addressed (Bowker et al. 2009). To relate this to Arctic information systems, a first theme that deserves more attention is the organization of the user-producer interface. It has been beyond the scope of this work to conduct interviews with users, which naturally forms a limitation of this analysis. It is increasingly recognized that interaction between users and service providers is key to salient services. Further research should therefore be particularly attentive to such dynamics as: How are users involved in the development of services and to what extent are they co-producers? In what ways are users sources of innovation? How do dynamics at the user-producer interface influence the 
successful uptake of a platform in the wider Arctic information infrastructure? Different users have different preferences and needs (Dawson et al. 2017, Lamers et al. 2018). Hence, it is important to study the conceptions of users and the design values that shape the development of the systems.

A second topic that requires in depth study is the continuous tension between standardization and flexibility in the development of information infrastructures (Hanseth et al. 1996). Standardization is required to provide consistent services to users. It is furthermore key to maximize compatibility and to enhance interoperability between systems and organizations, as well as to support coordination. Processes of standardization can also be interrupted with events that require standards to be flexible (Hanseth et al. 1996), such as the introduction of new communication technologies or changing legal frameworks. Further research should look into how organizations deal with this tension between standardization and flexibility and how that enables or constrains the development of services, as well as their quality.

A third theme concerns the long-term funding of the information platforms and its effects on the wider global "weather enterprise" (Thorpe 2016). As we have seen, funding has been a difficult issue in the establishment of service platforms, with BarentsWatch as the exception. It was, however, beyond the scope of this paper to address financial issues in detail, including the costs of developing new infrastructure, also in relation to (potential) use. Platform studies underscore that successful platform owners, such as Google and Facebook, manage to create and capture value through a specific business model (Langley and Leyshon 2017). Platform ecologies develop rapidly, fostered by the provisioning of ubiquitous connections, the sharing of user-generated content, programming possibilities, and the permitting of add-on applications developed by others. The platform owners can charge user fees for services, but the most profitable business is achieved by analyzing, aggregating and selling user data and space for targeted advertisements (Zuboff 2015). The Arctic information systems have not become large-scale and attractive platforms with such opportunities. However, with the increasing 'platformization' of infrastructures and the 'infrastructuralization' of platforms (Plantin et al. 2016), the Arctic information infrastructure may also be affected, and the public service character of the current information provisioning may be challenged. There is a potential conflict between the public and commercial interests of big and powerful companies. The issue of funding is therefore an important topic that needs further reflection and must be seen in the light of the major transformations that are taking place in the digital economy.

A final theme that calls for further exploration is the way in which information infrastructures alter the Arctic as a zone of risk. Information infrastructures have paradoxical tendencies: they mitigate risk through enabling informed decision-making, while they introduce new risks as the same time. In line with what Howe and colleagues (2016) argue, infrastructures have a set of presumptions regarding the future built into them. They are built to answer to current and projected opportunities and challenges in the Arctic that arise due to climate and environmental changes. Improved access to tailor-made information in the 
Arctic makes the area more accessible to a range of activities, thereby putting more strain on the region. A larger variety of vessel types and shipping activities can explore areas that have previously not been accessible. This not only increases the risks for the Arctic environment, but also for the vessels or shipping activities for two reasons. First, information systems or technology can break down, leaving these vessels in a relatively uninformed state. Second, other enabling factors in the Arctic, like search and rescue (SAR) services and infrastructures, do not develop at the same pace, which increases vessels' vulnerability in remote regions. As such, further research should reflect thoroughly on the potential risk-amplifying effects of improved information services and their associated governance challenges for sustainable Arctic activities.

\section{Acknowledgments}

This work was supported by the Fram Centre under Grant 66250/299. We wish to acknowledge our interviewees for sharing their knowledge and experience. This work has furthermore benefited from constructive discussions with many individuals, of whom we would like to thank David Arthurs, Helge Tangen, and Eivind Rinde in particular. We also acknowledge the work of three anonymous referees for their constructive suggestions that helped to improve an earlier version of this paper. Thanks to Onni Irish for proofreading the article. The views expressed in this paper are those of the authors. 


\section{References}

ACIA (2005). Arctic Climate Impact Assessment. Cambridge, Cambridge University Press: 1020.

AMAP (2017). Snow, Water, Ice and Permafrost. Summary for Policy-makers. Oslo, Arctic Monitoring and Assessment Programme.

Arbo, P., A. Iversen, M. Knol, T. Ringholm and G. Sander (2013). "Arctic futures: conceptualizations and images of a changing Arctic." Polar Geography 36(3): 163-182.

Bijker, W. E., T. P. Hughes, T. Pinch and D. G. Douglas (2012). The social construction of technological systems: New directions in the sociology and history of technology, MIT press.

Bowker, G. C., K. Baker, F. Millerand and D. Ribes (2009). Toward information infrastructure studies: Ways of knowing in a networked environment. International handbook of internet research, Springer: 97-117.

Dawson, J., W. Hoke, M. Lamers, D. Liggett, G. Ljubicic, E. Stewart and R. Thoman (2017). Navigating weather, water, ice and climate information for safe polar mobilities. Report prepared by the Polar Prediction Project's Societal and Economic Research and Applications Working Group (PPP-SERA) of the World Meteorological Organization (WMO) Geneva, World Meteorological Organization.

Dunn Cavelty, M. and K. S. Kristensen (2008). Securing'the Homeland': Critical Infrastructure, Risk and (In)Security. London, Routledge.

Duske, P. (2016). Geophysical Information Providers in the Arctic: Dynamics and Developments. Troms $\varnothing$, Norway, UiT The Arctic University of Norway: 32.

Edwards, P. N. (2010). A vast machine: Computer models, climate data, and the politics of global warming, Mit Press.

Edwards, P. N., S. J. Jackson, G. C. Bowker and C. Knobel (2007). Understanding infrastructure: dynamics, tensions, and design, NSF Report of a Workshop: History and theory of infrastructure: lessons for new scientific cyberinfrastructures.

Eicken, H. (2013). "Ocean science: Arctic sea ice needs better forecasts." Nature 497(7450): 431-433.

Flyvbjerg, B., N. Bruzelius and W. Rothengatter (2003). Megaprojects and risk: An anatomy of ambition, Cambridge University Press.

Hanseth, O., E. Monteiro and M. Hatling (1996). "Developing Information Infrastructure: The Tension between Standardization and Flexibility." Science, Technology, \& Human Values 21(4): 407-426.

Howard, R. (2009). The Arctic gold rush. London, Continuum.

Howe, C., J. Lockrem, H. Appel, E. Hackett, D. Boyer, R. Hall, M. Schneider-Mayerson, A. Pope, A. Gupta and E. Rodwell (2016). "Paradoxical infrastructures: ruins, retrofit, and risk." Science, Technology, \& Human Values 41(3): 547-565.

Hunt, J. (2013). "Meteorology in society and practical developments." Quarterly Journal of the Royal Meteorological Society 139(672): 561-572. 
Jung, T., N. D. Gordon, P. Bauer, D. H. Bromwich, M. Chevallier, J. J. Day, J. Dawson, F. Doblas-Reyes, C. Fairall and H. F. Goessling (2016). "Advancing polar prediction capabilities on daily to seasonal time scales." Bulletin of the American Meteorological Society 97(9): 1631-1647.

Kessides, I. (2004). Reforming infrastructure: Privatization, regulation, and competition, The World Bank.

Lamers, M., P. Duske and L. v. Bets (2018). "Understanding user needs: A practice-based approach to exploring the role of weather and sea ice services in European Arctic expedition cruising "Polar Geography

Lamers, M., A. Pristupa, B. Amelung and M. Knol (2016). "The changing role of environmental information in Arctic marine governance." Current Opinion in Environmental Sustainability 18: 49-55.

Langley, P. and A. Leyshon (2017). "Platform capitalism: the intermediation and capitalisation of digital economic circulation." Finance and society. 3(1): 11-31.

Lovecraft, A. L., C. Meek and H. Eicken (2013). "Connecting scientific observations to stakeholder needs in sea ice social-environmental systems: the institutional geography of northern Alaska." Polar Geography 36(1-2): 105-125.

Lovecraft, A. L., C. Meek and H. Eicken (2016). "Data Portals as Institutional Bridges: Connecting Scientific Observations to Stakeholder Needs in Sea Ice Social-Environmental Systems." Arctic Observing Summit: 15-18.

Mayntz, R. and T. P. Hughes (1988). The Development of Large Technical Systems. Frankfurt am Main/New York, Campus Verlag.

MET Norway (2015). Været til sjøs. Brukerundersøkelse om maritime værtjenester. K. Gjesdal, K. Goa, A. M. Olsen and T. Olsen. Bergen, Meteorogisk Institutt. no. 15/2015

Nilsen, Y. and M. Vollset (2016). Vinden dreier. Meteorologiens historie i Norge. Oslo, Spartacus forlag/Scandinavian Academic Press.

Overpeck, J. T., G. A. Meehl, S. Bony and D. R. Easterling (2011). "Climate data challenges in the 21st century." science 331(6018): 700-702.

Plantin, J.-C., C. Lagoze, P. Edwards, N. and C. Sandvig (2016). "Infrastructure studies meet platform studies in the age of Google and Facebook." New Media \& Society 20(1): 293-310.

Pulsifer, P., S. Gearheard, H. P. Huntington, M. A. Parsons, C. McNeave and H. S. McCann (2012). "The role of data management in engaging communities in Arctic research: overview of the Exchange for Local Observations and Knowledge of the Arctic (ELOKA)." Polar Geography 35(3-4): 271-290.

Pulsifer, P., L. Yarmey, Ø. Godøy, J. Friddell, M. Parsons, W. Vincent, T. d. Bruin, W. Manley, A. Gaylord and A. Hayes (2014). "Towards an International Polar Data Coordination Network." Data Science Journal 13(0).

Pulsifer, P., L. Yarney, Ø. Godøy, J. Friddell, W. Vincent, T. DeBruin and M. Parsons (2013). "Data management for Arctic observing." Arctic Observing Summit, White Paper.

Rojo, M., C. Claud, P.-E. Mallet, G. Noer, A. M. Carleton and M. Vicomte (2015). "Polar low tracks over the Nordic Seas: a 14-winter climatic analysis." Tellus $A 67$. 
Sale, R. and E. Potapov (2010). The scramble for the Arctic: ownership, exploitation and conflict in the Far North. London, Francis Lincoln.

Samuelsen, E. M., K. Edvardsen and R. G. Graversen (2017). "Modelled and observed sea-spray icing in ArcticNorwegian waters." Cold Regions Science and Technology 134: 54-81.

Schneider, V. and A. Jäger (2003). "The privatization of infrastructures in the theory of the state: an empirical overview and a discussion of competing theoretical explanations." On Creating Competition and Strategic Restructuring: Regulatory Reform in Public Utilities, Cheltenham: Edward Elgar.

Smith, L. C. and S. R. Stephenson (2013). "New Trans-Arctic shipping routes navigable by midcentury." Proceedings of the National Academy of Sciences 110(13): E1191-E1195.

Star, S. L. (1999). "The ethnography of infrastructure." American behavioral scientist 43(3): 377-391.

Stephenson, S. R., L. C. Smith and J. A. Agnew (2011). "Divergent long-term trajectories of human access to the Arctic." Nature Climate Change 1(3): 156-160.

Stewart, E., A. Tivy, S. Howell, J. Dawson and D. Draper (2010). "Cruise tourism and sea ice in Canada's Hudson Bay region." Arctic: 57-66.

Thorpe, A. (2016). "The Weather Enterprise: A Global Public-Private Partnership." World Meteorological Organization Bulletin 65(2).

Van Vliet, B., E. Shove and H. Chappells (2012). Infrastructures of consumption: Environmental innovation in the utility industries, Earthscan.

Winner, L. (1993). "Upon opening the black box and finding it empty: Social constructivism and the philosophy of technology." Science, Technology, \& Human Values 18(3): 362-378.

Zuboff, S. (2015). "Big other: surveillance capitalism and the prospects of an information civilization." Journal of Information Technology 30(1): 75-89. 